\title{
Diffusion of Spatial Data Infrastructures: Private More Inspired than the Public Sector-A Case of Tanzania
}

\author{
Martine Hagai \\ Department of Geospatial Sciences and Technology, Ardhi University, Dar es Salaam 35176, Tanzania
}

\begin{abstract}
Spatial data is a key resource for national development. There is a lot of potential locked in spatial data and this potential may be realized by making spatial data readily available for various applications. SDI (Spatial Data Infrastructures) provides a platform for the data users, producers and so on to generate and share spatial data effectively. Though efforts to develop spatial data infrastructures started worldwide in the late 1970s, SDIs are still perceived by many institutions as new innovation; as such, they have not penetrated to all institutions to bring about effective management and development changes. This paper is reporting on a study conducted to assess SDI Readiness Index for Tanzania. The study aimed at identifying problems undermining SDI implementation in Tanzania, despite its potential in bringing fast socio-economic development elsewhere in the world. This paper is based on a research based on views from stakeholders of geospatial technology industry in Municipal Councils, Private Companies and Government Departments in Tanzania. Results indicated that Private Companies are more inspired than Government institutions towards implementation of SDIs. And those problems affecting implementation of SDIs are lack of National SDI Policy, lack of awareness and knowledge about SDIs, limited funding to operationalise SDI, lack of institutional leadership to coordinate SDI development activities, lack of political commitment from the Government. It is recommended that delibate efforts be devised to raise awareness of SDI amongst the Tanzanian community.
\end{abstract}

Key words: Spatial data, SDI (Spatial Data Infrastructure), SDI Readiness Index, SDI Readiness factors.

\section{Introduction}

There are several definitions of SDI (Spatial Data Infrastructure) depending on which view the emphasis is placed on. Some definitions put emphasis on either technical, data or organizational or a combination of all. Focusing on a definition which places emphasis on combination of all views, it may be defined as an umbrella of policies, standards and procedures under which organizations and technologies interact to foster sharing of $s$ of spatial data [1].

Evolution of SDI has reference to the UN (United Nation) Resolution 69/266, as adopted by the General Assembly on 26 Feb. 2015, titled Global Geodetic framework for sustainable development, which called for putting in place measures to reverse adverse effects of environmental degradation as a result of

Corresponding author: Martine Hagai, Ph.D., research fields: geoinformatics, remote sensing and GIS (Geographic Information Systems). deforestation, pollution, depletion of natural resources, mismanagement of toxic wastes and so on.

In the course of addressing the UN Resolution, it was noted that geoinformation availability was critical for its realization. Additionally, geoinformation has a significant economic value and policy value, as it enables the integrated assessment of policies from different sectors (such as agriculture, transport, regional development, environment, etc. [2]). To that effect, many countries have embraced development of NSDIs (National Spatial Data Infrastructures) to foster sharing of spatial data, ready for processing them into geoinformation for various applications. Unfortunately to-date, Tanzania has not developed NSDIs. Indeed, Tanzania has no NSDI policy which ought to define premises for legal and operational procedures for spatial data sharing.

However, Tanzania has a National ICT (Information and Communication Technology) Policy, which though alludes inter-llia on multilayered cooperation 
and knowledge sharing, it does not explicitly spell out spatial data handling and sharing issues, which are fundamental in harnessing the potential of the ICTs so as to bring about fast national socio economic development, such as realization of E-Governance initiative, application of the knowledge-based economy, facilitation of evidence based decision making for sustainable national development and so on. Clearly, this testifies that it may take some time for Tanzania to implement SDI due to lack of supportive technical framework. Nevertheless, there have been efforts towards development of Tanzania NSDIs which started way back in 2003 [3].

A number of African Countries including Kenya, Uganda, Zimbabwe, Namibia, Mozambique, Botswana, Lesotho, Ethiopia, Nigeria, Ghana and Libya to mention but a few, have started developing and implementing their NSDI. The main challenge in Tanzania is who is to take the lead/coordinating role in developing SDIs in Tanzania. Lack of a coordinating body is attributed to the fact that SDI matters are of a cross cutting nature, as such, they are multidisciplinary. As such, it is not clear which sector is more eligible to take up the SDI leading/coordinating role. This is a challenge to the fast socio-economic growing Tanzania and hence the essence of this paper, which is focusing on assessing SDI Readiness Index for Tanzania. SDI Readiness Index is defined to be a degree to which an entity is prepared and/or inspired to participate in a networked data sharing/exchange environment [4].

Finally, the paper attempts to identify problems undermining SDI development in Tanzania, with a view of proposing a solution towards implementing SDI in Tanzania [5].

\section{Methodology}

The study was based on evaluation of SDI readiness of selected sites, which were cities of Dar es Salaam, Mbeya and Mwanza in Tanzania. Targeted stakeholders were Government Institutions, Private Organizations/Companies,

Non-governmental
Organizations and Civil Societies in above mentioned cities.

Specifically the study focussed on the following factors:

1. Stakeholder's perception on the relevance of implementation of SDI and their socio-economic importance;

2. Stakeholder's capacities in generating spatial data and metadata as well as existence of:

a. structured data collection procedures \& standards;

b. adequate information and communication technology hardware and software;

c. human resources;

d. financial base to support implementation of SDI.

3. Stakeholder's behavioural willingness of their institutions towards implementation of SDIs.

Data was collected using questionnaires designed to capture attitudes, motivation and perception. Additionally, the questionnaires aimed at assessing readiness indictors as expressed by intrinsic attributes as defined by pre-existing infrastructures (e.g. technical, human ware, access networks, financial resources, etc.) as well as extrinsic factors defined by stereotype myths, cultural/or organizational and behavioral barriers influences on SDI implementation in Tanzania. All data collected were processed using SPSS (Software Package). SDI_Index is inserted in math type.

\section{Results and Analysis}

SDI Readiness determination is a multicriteria decision making problem [6], as such, it involves disaggregation of global factors into several decision criteria iteratively until each factor is well defined. To that effect, intrinsic factors were evaluated on the basis of Rajabifard Model [7]. The Model is based on describing SDI on the basis of existing status of hardware and software components supportive of SDI (ibid).

Extrinsic factors were evaluated on the basis of TAM (Technological Acceptance Model) (ibid), which focuses on people's behavior. Indeed, it is 
based on the thesis that future use of new technology depends on user's behavioral intension to use the technology. Essentially TAM establishes willingness for change on the basis of following factors:

- Perceived usefulness of the technology;

- Perceived ease of use of the technology;

- Attitude towards use of the technology;
- Behavioral intension to use of the technology.

As all the above factors are naturally qualitative, they were assigned non-subjective numeric certainty values so as to make them quantitative. Thereafter all the factors considered were combined using a fuzzy-based multivalent logic SDI model (ibid), which is stated verbatim hereunder as:

$$
\begin{aligned}
& S D I_{-} \text {Index }=(O v * O l * O a)^{\frac{1}{3}} *(I c * \operatorname{Im} 2)^{\frac{1}{2}} *(P c * P S * P l)^{\frac{1}{3}} *\left(1-((1-F g) *(1-F p) *(1-F r))^{\frac{1}{3}} *((A t * A w\right. \\
& \left.*\left(1-((1-A s) *(1-A d) *(1-A o))^{\frac{1}{3}}\right)^{\frac{1}{3}}\right)^{\frac{1}{2}}
\end{aligned}
$$

\section{Where:}

At - technology availability;

Aw-web connectivity;

As_-geospatial availability;

Ad—own software development;

Ao-development of open source culture.
Some of the results from analysis of data from the questionnaires from institutions/companies surveyed are presented in Fig. 1.

Results of the rest of factors are presented in Tables $1-3$.

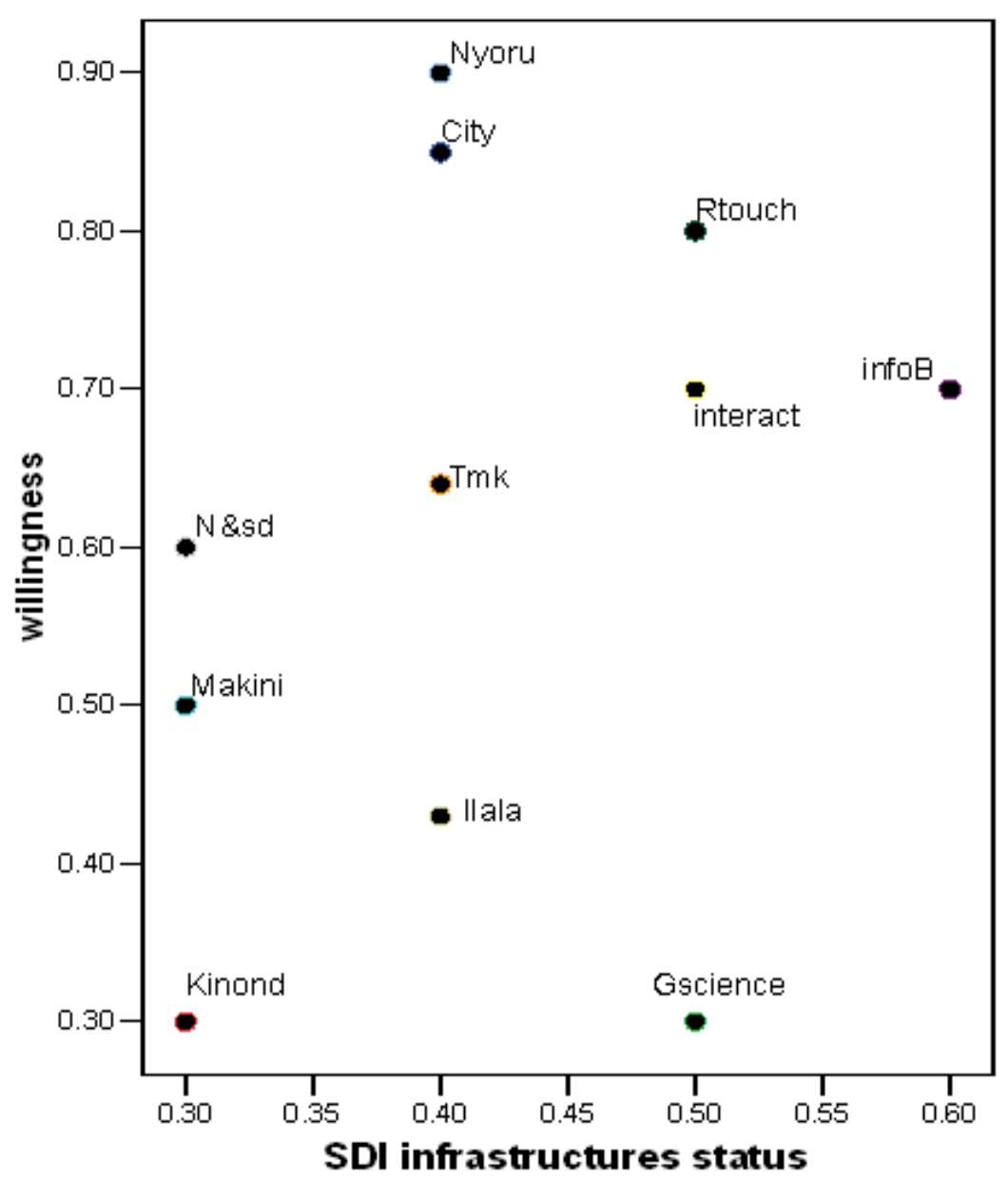

Fig. 1 Scatter diagram for SDI willingness on the basis of infrastructure for institutions in Dar es Salaam city. 
Public Sector-A Case of Tanzania

Table 1 Summary of SDI Readiness factors assessment for institutions in Dar es Salaam city.

\begin{tabular}{llllllll}
\hline $\begin{array}{l}\text { Name of } \\
\text { Organization/Company }\end{array}$ & Organization & Information & $\begin{array}{l}\text { Human } \\
\text { capacity }\end{array}$ & $\begin{array}{l}\text { Financial } \\
\text { resource }\end{array}$ & $\begin{array}{l}\text { Comm. } \\
\text { technology }\end{array}$ & $\begin{array}{l}\text { SDI Readiness } \\
\text { Index }\end{array}$ & $\begin{array}{l}\text { Relative SDI } \\
\text { Readiness Index }\end{array}$ \\
\hline Public institutions & 0.29 & 0.30 & 0.45 & 0.30 & 0.63 & 0.38 & $46.3 \%$ \\
Private institutions & 0.36 & 0.57 & 0.40 & 0.38 & 0.62 & 0.43 & $53.8 \%$ \\
\hline
\end{tabular}

Table 2 Summary of SDI Readiness factors assessment for institutions in Mbeya city.

\begin{tabular}{llllllll}
\hline $\begin{array}{l}\text { Name of } \\
\text { Organization/Company }\end{array}$ & Organization & Information & $\begin{array}{l}\text { Human } \\
\text { capacity }\end{array}$ & $\begin{array}{l}\text { Financial } \\
\text { resources }\end{array}$ & $\begin{array}{l}\text { Comm. } \\
\text { technology }\end{array}$ & $\begin{array}{l}\text { SDI Readiness } \\
\text { Index }\end{array}$ & $\begin{array}{l}\text { Relative SDI } \\
\text { Readiness Index } \\
(\%)\end{array}$ \\
\hline Public institutions & 0.38 & 0.18 & 0.24 & 0.25 & 0.41 & 0.28 & $43.8 \%$ \\
Private institutions & 0.22 & 0.27 & 0.30 & 0.52 & 0.63 & 0.36 & $56 \%$ \\
\hline
\end{tabular}

Table 3 Summary of SDI Readiness factors assessment for stakeholders in Mwanza city.

\begin{tabular}{llllllll}
\hline $\begin{array}{l}\text { Name of } \\
\text { Organization/Company }\end{array}$ & Organization & Information & $\begin{array}{l}\text { Human } \\
\text { capacity }\end{array}$ & $\begin{array}{l}\text { Financial } \\
\text { resources }\end{array}$ & $\begin{array}{l}\text { Comm. } \\
\text { technology }\end{array}$ & $\begin{array}{l}\text { Institutional SDI } \\
\text { Readiness Index }\end{array}$ & $\begin{array}{l}\text { Relative SDI } \\
\text { Readiness Index } \\
(\%)\end{array}$ \\
\hline $\begin{array}{l}\text { Public institutions } \\
\text { Private institution }\end{array}$ & 0.38 & 0.18 & 0.24 & 0.25 & 0.41 & 0.28 & $44 \%$ \\
\hline
\end{tabular}

3.1 Observed Limiting Factors for Implementation of Sdis in Tanzania

On the basis of respondents' views and analysis, following factors were noted as limiting the implementation of NSDI in Tanzania:

1. Lack of a National SDI Policy;

2. Lack of institutional leadership;

3. Lack of awareness and knowledge about SDI;

4. Lack of political commitment;

5. Limited funding to sustain SDI.

\section{Conclusions}

Dar es Salaam city is relatively highly inspired towards SDIs implementation than Mbeya and Mwanza cities. This is partly due to the fact that it hosts most business and as a result, it generates more than $75 \%$ of the National GDP. On the basis of this, findings from Dar es Salaam are sufficient and adequate representative of the entire Tanzania;

About 64, 33 and $28 \%$ of institutions surveyed in Dar es Salaam, Mbeya and Mwanza respectively indicated to be ready to support implementation of SDIs;

There is a general apathy amongst institutions to share/exchange data mainly due to lack of knowledge and education about SDI and more importantly is the problem of unclear cost benefits of investmenting in SDI;

In general, private companies are relatively more inspired towards implementation of SDI.

\section{Recommendations}

There is a need of intensifying efforts for raising SDI awareness amongst stakeholders and decision makers on its importance for national socio-economic development. Additionally, efforts to develop a National SDI Policy need to be intensified from all stakeholders [8].

As best practices cannot be equitably realised in all municipal councils or government instutions, due to variations in organization, technologies, financial capabilities and so on, it is being recommended that so long as pubulic sectos is lagging behind towards implementation of SDI, this is a clear testimony that there is limited knowledge about SDI within the government mechinery, as such delibarate strategies should be devised to raise SDI awareness and knowledge to the entire Tanzanian community.

\section{References}

[1] Philips, A., Williamson, I., and Ezigbalike, C. 1999. "Spatial Data Concepts." The Australian Surveyor 44 (1): 
28-30.

[2] Kalande, W., and Ondolo, J. D. 2006. "Geoinformation Policy in East Africa." In Preceedings XXIII FIG Congress: 8-13. Munich, Germany.

[3] Masele, Z., and Mtalo, E. G. 2004. "SDI Initiatives in Tanzania." Presentation at SADC SDI Workshop, Pretoria, South Africa.

[4] Kok, B., and Van Loenen, B. 2005. "How to Assess the Success of National Spatial Data Infrastructures?" Computers, Environment and Urban Systems 29 (6): 699-717.

[5] Ezigbalike, C., Selebalo, Q. C., Faiz, S., and Zhou, S. Z. 2000. "Spatial Data Infrastructures: Is Africa Ready?" Presented at the 4th Spatial Data Infrastructure
Conference, Cape Town South Africa.

[6] Delgado Fernandez, T., Lance, K., and Buck, M. 2005. "Assessing an SDI Readiness Index, from Pharaohs to Geoinformatics, FIG Working Week 2005 and 8th International Conference on Global Spatial Data Infrastructure." April, Cairo, Egypt.

[7] Kulvers, W. 2007. "Implementing Local Spatial Data Information: Are Municipalities Inspired?" M.Sc. thesis, Manchester Metropolitan University (UNIGIS), Manchester.

[8] Rajabifard, A. 2002. "Diffusion of Spatial Data Infrastructures: With Particular Reference to Asia and the Pacific." Ph.D. thesis. Accessed May 10, 2017. http://www.geom.unimelb.edu.au/research/publications/R ajabifard_thesis.pdf. 